\title{
2-D Electrical Resistivity Monitoring of a Municipal Solid waste Dumpsite in Port Harcourt, Nigeria
}

\author{
C.N. Ehirim ${ }^{1}$ and J.O. Ebeniro ${ }^{2}$ \\ Geophysics Research Group, Department of Physics, University of Port Harcourt, P.O.Box 122, Choba, Port \\ Harcourt, Nigeria
}

\begin{abstract}
Electrical resistivity tomography (ERT) was carried out around a municipal solid waste dumpsite with the objective of monitoring spatial and temporal variations of dumpsite emissions in soil and groundwater along four (4) traverse lines. Results show that the baseline exhibits less spatial and temporal variations in resistivities than the monitor data along each traverse. The study revealed that the dumpsite was in its exothermic phase of activity in the first two years of active waste dumping and endothermic at the cessation of waste dumping and final reclamation after four years of operation. The exothermic phase was characterized by the production of enormous volumes of leachate and relatively conductive waste gases, predominantly Carbon dioxide $\left(\mathrm{CO}_{2}\right)$, Hydrogen sulphide $\left(\mathrm{H}_{2} \mathrm{~S}\right)$ and Ammonium $\left(\mathrm{NH}_{3}\right)$, by infiltrating rainwater through the waste pile, groundwater inflow and aerobic decomposition of waste matter. The endothermic phase is accompanied by the production of more waste gases than leachate, especially the non-conductive methane gas $\left(\mathrm{CH}_{4}\right)$ and nonmethane volatile organic compounds (VOCs) by the anaerobic decomposition of waste matter due to compaction effects resulting in the inhibition of the circulation of oxygen-rich air within the waste pile. The dump was observed to be at the peak of its methanological phase during the endothermic cycle. This is especially pronounced in the resistivity of the monitor data situated at the edge of the dumpsite, which exhibits anomalously high resistivities compared to the baseline due to increased non-conductive methane gas generation, VOCs, and reduced temperature within the dump. The reference data exhibits intermediate resistivities relative to the traverses closer to the dumpsite. The waste gases dominate at this offset, while the impact of leachate has considerably reduced.
\end{abstract}

Key Words: Electrical Resistivity Tomography (ERT), Baseline data, Monitor data, Dumpsite, and Solid waste

\section{Introduction}

The growing level of ground water contamination due to poor waste management practices in Nigeria is assuming an alarming proportion. This has become a source of worry and serious concern to the provincial governments in the country, as regards to the provision of adequate potable water supply to its growing population. Port Harcourt is a cosmopolitan coastal city, with high population density arising from overwhelming oil related, industrial and commercial activities. As such, diverse hazardous and non- hazardous wastes are generated which must be deposited off safely.

The city lacks surface fresh water sources which could be impounded into dams for potable water supply, and therefore, is heavily dependent on ground water sources for its domestic, industrial and agricultural uses. Ground water resources in the city is however, highly vulnerable to salt water intrusion and surface induced contamination from solid waste dump sites. This is primarily due to its proximity to the coast, shallow nature of its aquifers, permeable soil media and flat topography [1].

Solid wastes are disposed off indiscriminately into open dumps and un-engineered landfills in the city without adequate pre-impact assessment in relation to soil and ground water conditions. This presents long term threats to ground water quality through leachate and associated waste gas contamination. The composition of these dumpsite emissions is a function of the variability of the waste itself, climate, hydrogeological setting and time. This variability in composition with time is fundamental in the monitoring and assessment of impacts in and around dumpsites.

The impact of landfill leachate on ground water has given rise to a number of studies in recent years ([2], [3], and [4]). Leachates usually have sufficiently high contrast in physical properties against the host media due to increased dissolved salts in the ground water and resulting decrease in pore water resistivity. Therefore, they could be detected by the geoelectrical technique [5].

Changes in pore fluid saturation and composition, and temperature induced changes in the soil and ground water conductivities can be monitored by repeated ERT surveys. Analysis of electrical images derived at specific intervals of time from spatially distributed resistance data provides insights into rapidly occurring subsurface processes based on surface measurements. Electrical resistivity tomography allows real time measurement of geoelectrical properties of vulnerable ground water systems. It is now routinely deployed to 
monitor temporal and spatial variation of contaminant migration within and around solid waste landfills ([6], [7]).

Baseline ERT studies was carried out in and around the dumpsite in February 2008. Results revealed that the surrounding soil and ground water has been contaminated by leachate plumes and waste gases exhibiting anomalously low and high resistivities, respectively. These waste emissions has penetrated to depths exceeding $31 \mathrm{~m}$, which is well within the ground water aquifer and has migrated $40 \mathrm{~m}$ offset from the edge of the landfill to the SE [8]. As a result of this revelation, a repeat / monitor survey was carried out by February 2012, with the objective to monitor the spatial and temporal variations in leachate and waste gas generation, composition and migration over this time lapse.

Since there are no changes in lithology and porosity of the underlying geologic formation, the ERT anomalies can be related to fluid saturation, composition and temperature changes, such that the comparison of the baseline and monitor data is reduced to estimating changes in pore fluid saturation, composition and temperature in and around the dumpsite within this time lapse.

\section{Location of the site}

The dump site in the present study is located at the Obiri Ikwere road junction along the East West road, and covers a total area of about $0.15 \mathrm{Km}^{2}$. It is delineated between latitude $4^{0} 52.36^{1}$ to $4^{0} 52.75^{1} \mathrm{~N}$ and longitude $6^{0} 57.17^{1}$ to $6^{0} 57.43^{1} \mathrm{E}$ (Fig.1.0). The area is accessible through networks of tarred and untarred motorable roads and tracks which were used for the geophysical survey.

The study area is moderately vegetated with almost flat topography. It is characterized by alternate wet and dry seasons, with a total annual rainfall of about $240 \mathrm{~cm}$, relative humidity of over $90 \%$ and mean annual temperature of $27^{0} \mathrm{C}$ [9].

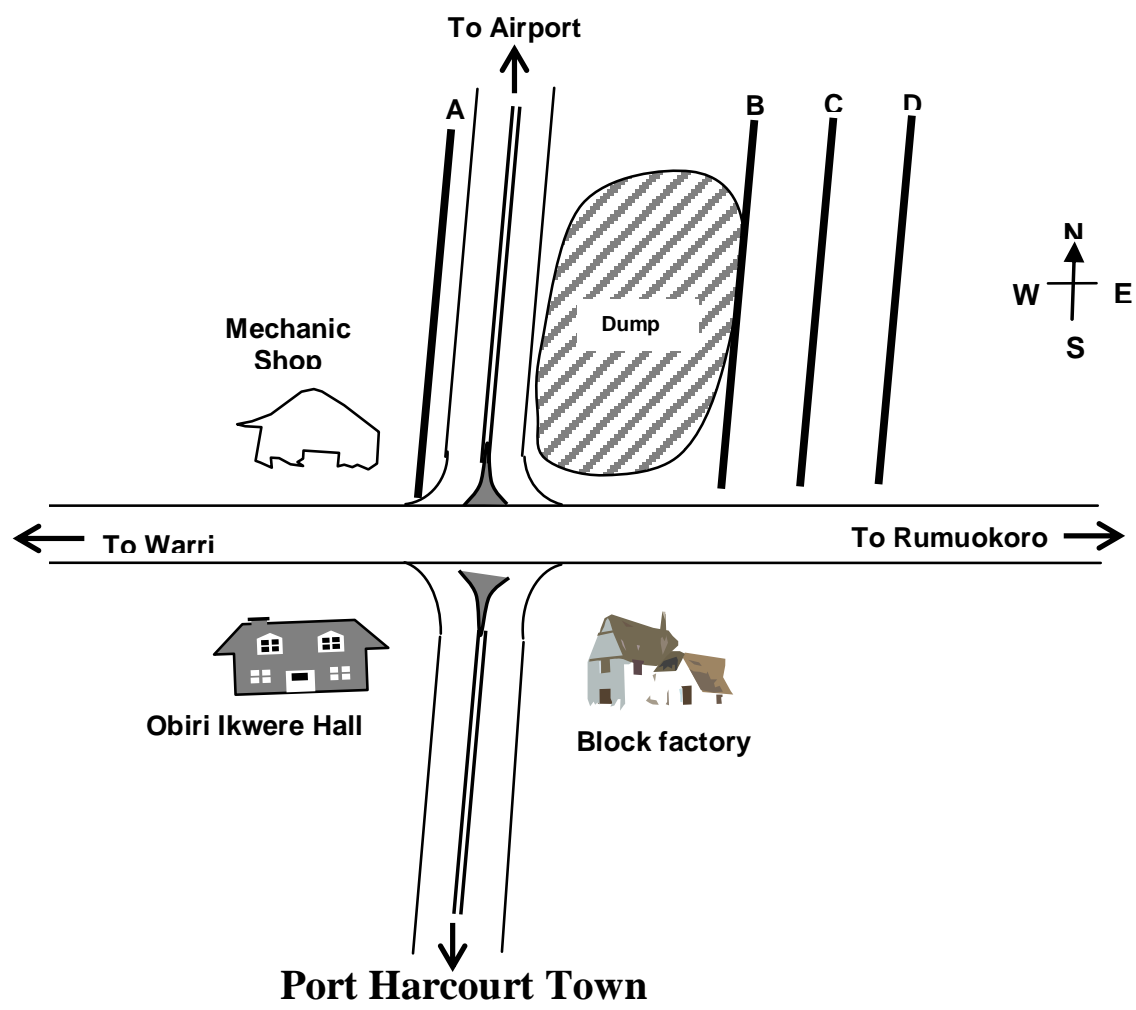

Fig.1.0: Location map of the area showing the dumpsite and traverse lines

III. Geology and Hydrogeology of the site

The local geology of the dump site consists of stratified sediments of the Niger delta Benin Formation, underlain by the paralic Agbada and marine Akata Formations (Fig. 2.0). The Benin formation is a continental deposit of probably upper deltaic depositional environment and the main water bearing formation in the area [10].

The Formation consists of dominantly unconsolidated moderately porous and permeable sands with lenticular clays and shales at depth. The depth to the water table ranges between 3 to $15 \mathrm{~m}$, depending on the time of the year. Potable groundwater aquifer conditions from nearby boreholes around the dumpsite occur at depths varying between 28 to $45 \mathrm{~m}$ below the water table. This is used as the water supply aquifer for the residents around the dumpsite area and most part of the city. The aquifer obtains steady recharge mostly by 
direct precipitation with maximum infiltration at the peak of the rainy season. With the flat topography, moderate vegetation cover and moderately porous and permeable soil cover, runoff and other losses are minimized and much of the precipitated water goes into storage.

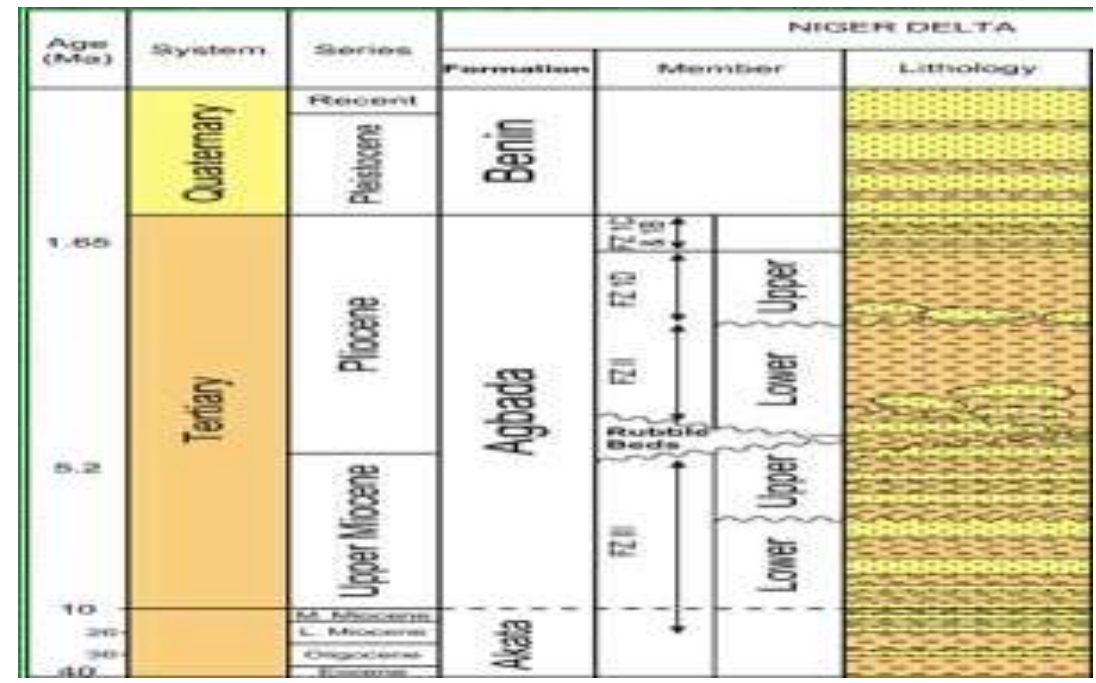

Fig. 2.0: Geologic and Stratigraphic map of the area

\section{Methodology}

Electrical resistivity tomography (ERT) surveys were carried out with a digital readout ABEM Terremetre SAS (Signal Averaging System) 1000C, using the Wenner- $\alpha$ electrode configuration. Four traverse lines A-D (Fig. 1.0), each of length $200 \mathrm{~m}$ were occupied with inter traverse spacing of $20 \mathrm{~m}$ for the baseline and repeat / monitor surveys after forty eight (48) calendar months, while maintaining the same electrode spacing's and positions. In order to account for the natural variations and possible contaminant migration during this time lapse, additional traverse (E) were occupied at $60 \mathrm{~m}$ offset to the SE from the dumpsite.

Measurements were made using twenty (20) stainless steel electrodes with increasing electrode distances (a-spacing) along traverses ranging from 10 to a maximum of $60 \mathrm{~m}$. The electrodes were moved from one end of the line to the other in a lip frog manner to achieve continuous horizontal coverage of the subsurface. Currents were injected into the ground via two current electrodes $(\mathrm{C} 1$ and $\mathrm{C} 2)$ located at the exterior of the potential electrodes (P1and P2). The potential difference between the potential electrodes was measured and the resistance of the ground were calculated automatically by the meter and displayed.

After taking the first readings along traverse A at 1a spacing, spacing's of $2 \mathrm{a}, 3 \mathrm{a}, 4 \mathrm{a}, 5 \mathrm{a}$ and $6 \mathrm{a}$ was acquired along the same traverse to build pseudo sections of the lateral and vertical variation in subsurface resistivity (Fig.3.0). This process was repeated until traverses B, C, and D were occupied.

The resistance values obtained was converted into apparent resistivity values using the equation:

$\rho_{\mathrm{a}}=2 \pi \mathrm{aR}$

where $\mathrm{a}=$ Electrode spacing

$\mathrm{R}=$ Resistance of the ground

The resulting $\rho_{\mathrm{a}}(\Omega \mathrm{m})$ were recorded in a recording sheet for subsequent processing and interpretation.

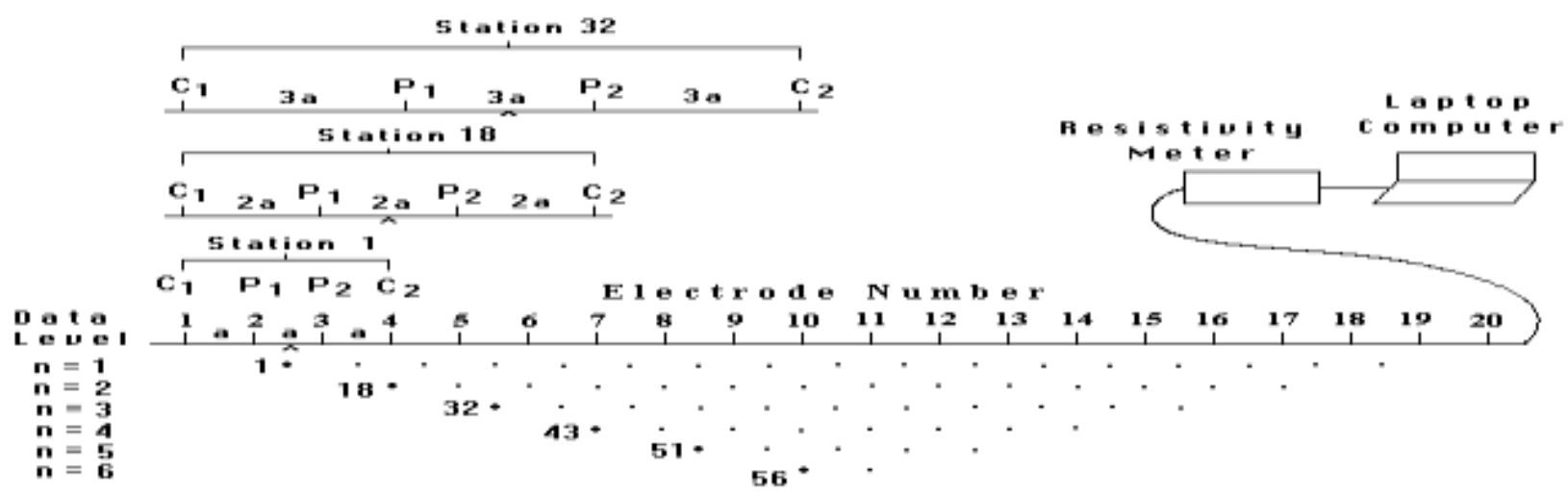

Fig. 3.0: The arrangement of electrodes in ERT survey [11] 


\section{Presentation of results}

The acquired data (Base and Monitor) was processed using the RES2DINV inversion software. They were inverted independently using a finite element approach to the forward model and least squares optimization technique to generate the true resistivity distribution of the subsurface [11].

The results of the ERT images are displayed as two dimensional (2-D) inverse model sections of true resistivity distributions along the traverses (Fig. 4.0). The root mean square (RMS) errors of the inverted data vary from 2.1 to $9.5 \%$, a reflection of the degree of fit between the calculated and field data. The time difference images were visually compared to detect changes in subsurface electrical properties within the time lapse related to changes in pore fluid saturation, composition and temperature in the subsurface.

Feb. 2008 2-D images (Baseline)



Fig. 4.0: 2-D ERT images (Base and Monitor) along A, B, C and D traverses

The study delineated subtle changes in resistivity which varies between the February 2008 data (Baseline) and February 2012 data (Monitor). General observation revealed appreciable increases in the resistivities in time, space and offset from the dumpsite. This is especially pronounced in the monitor compared to the baseline inverse models. The resistivities varies from $<25.4$ to $>6418 \Omega \mathrm{m}$ in the baseline and $<64.5$ to $>$ $10,673 \Omega \mathrm{m}$ in the monitor.

Two distinctive anomalous zones were delineated in the time difference images. These are low and high resistivity anomalies. The low resistivity anomalies (deep blue) varies in resistivity from $\langle 25.4$ to $>$ $528 \Omega \mathrm{m}$ in the baseline and $<64.5$ to $>1,178 \Omega \mathrm{m}$ in the monitor data. The high resistivity anomalies (purple to 
pink) varies from 1,387 to $>6,418 \Omega \mathrm{m}$ in the baseline and 2,322 to $>10,673 \Omega \mathrm{m}$ in the monitor data. These low and high resistivity anomalies penetrated the groundwater aquifer at subsurface depth of about $31 \mathrm{~m}$. They are interpreted as leachate and waste gas contamination of the soil and ground water, respectively, in the investigated dumpsite.

In general, the lowest resistivity anomalous zones at all depth levels and offsets were isolated in the baseline and highest resistivity anomalous zones in the monitor inverse models. These changes in resistivity show the effects of dilution, recharge of solutes and variations in temperatures with offsets from the dumpsite within this time lapse.

In other to account for the natural variation and possible contaminant migration, a control survey was acquired at $60 \mathrm{~m}$ offset from the dumpsite to the SE (Fig.5.0). The result of the reference data reveals moderate resistivities relative to the profiles closer to the dumpsite. The impact of the waste gases is pronounced at this offset, while that of the leachate is reduced. This suggests the relatively small impact of the dumpsite at this offset.

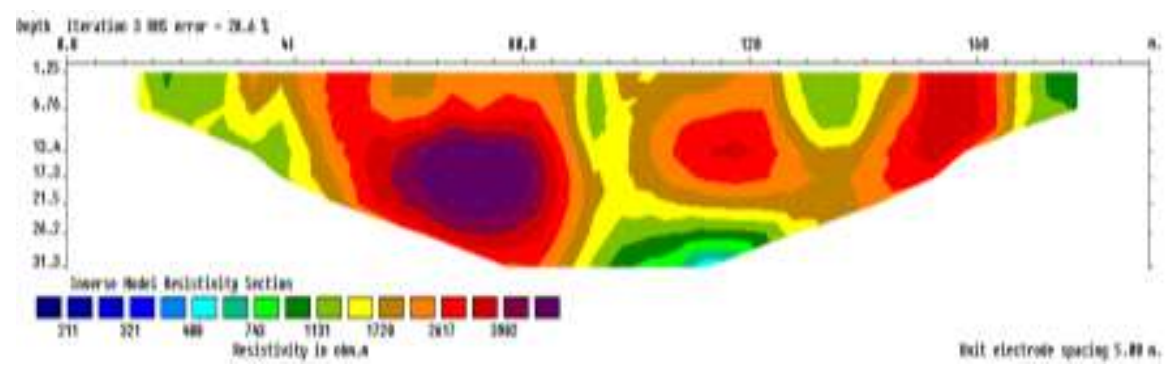

Fig. 5.0: 2-D ERT image (Control)

\section{Discussion of results}

Electrical resistivity tomography (ERT) has successfully been implemented in the monitoring of dumpsite emissions in soil and groundwater around a municipal solid waste dumpsite. This involves a repeat 2D ERT surveys along the same traverse lines and electrode positions over forty eight (48) calendar months. The two data sets comprising of the February 2008 baseline and February 2012 monitor data were inverted independently and visually compared to monitor spatial and temporal changes in subsurface electrical properties related to changes in fluid saturation, composition and temperature.

The baseline exhibits less spatial variation in resistivity than the monitor data at all depth levels and offsets from the dumpsite. This is either by diminution or enhancement of resistivity structures, both laterally and vertically over this time lapse. Temporal changes in resistivity were clearly detected in both the baseline and monitor data, and were especially pronounced in the traverses closest to the dumpsite. The highest resistivities were isolated in the monitor traverses and lowest in the baseline.

Leachate is produced by infiltrating water through the waste pile, groundwater inflow and by the aerobic decomposition of waste matter by micro-organisms. This produces in addition carbon dioxide $\left(\mathrm{CO}_{2}\right)$, hydrogen sulphide $\left(\mathrm{H}_{2} \mathrm{~S}\right)$ and water $\left(\mathrm{H}_{2} \mathrm{O}\right)$, with nitrate and ammonia $\left(\mathrm{NH}_{3}\right)$ via a number of intermediate products within the first two years of waste dumping. This oxidation reaction is exothermic, as a result, temperature in the landfill is elevated, enhancing ionic mobility in the fluids permeating the pore spaces of the rocks and reduces the electrical resistivity in the subsurface layers. This explains the low resistivity of the baseline data compared to the monitor along traverse B situated at the edge of the dumpsite, which increases with offsets in all the other traverses.

Compaction of waste due to overburden waste mass, road construction and reclamation activities in the dump at the fourth year, results in the inhibition of the circulation of oxygen-rich air within the waste pile. This results in anaerobic decomposition of waste matter by micro-organisms within the waste pile, with the production of more landfill gases than leachate, especially the non-conductive methane and non-methane volatile organic compounds (VOCs). This reduction reaction is endothermic and temperature in the land fill is reduced, which decreases ionic mobility and further increases the resistivity of non-conductive methane and non-methane VOCs.

This explains why the monitor data along the profiles exhibits anomalously high resistivities over this time lapse compared to the baseline. The result of traverse B at the edge of the landfill for the monitor is most outstanding. This revelation suggests that over this time lapse, the dumpsite was at the peak of its methanological phase, where non-conductive methane gas and non-methane volatile organic compounds (VOCs) are produced at the expense of leachate under anaerobic conditions.

These changes in resistivity of the baseline and monitor data with offsets from the dumpsite are attributed to natural attenuation processes of dilution and dispersion, which results to changes in solute concentration. This can also be attributed to decreasing temperature with offset from the dumpsite, which 
enhances the bubbling out of solution of dissolved waste gases, reduced ionic mobility's, as well as the soil physical properties which concentrate some solutes in preference to others.

The reference data exhibit intermediate resistivities relative to the profiles closer to the dumpsite. At the upper part of the reference data, natural soil conditions appear to be stabilizing, while the high resistivity anomaly is dominant with increasing depth at this offset. This suggests possible bubbling out of solution of waste gases from dissolved leachate in ground water due to reduced temperatures with increasing offset from the land fill. However, the impact of leachate on soil and ground water has greatly been reduced at this offset.

\section{Conclusion}

ERT surveys were carried out to monitor spatial and temporal changes in dumpsite emissions due to a municipal solid waste dumpsite. The study revealed that the dumpsite was in its exothermic phase in the first two years of active waste dumping and endothermic when waste dumping has stopped and the dumpsite was compacted and reclaimed after four years.

The exothermic phase is characterized by the production of enormous volumes of leachate and waste gases $\left(\mathrm{NH}_{3}, \mathrm{CO}_{2}\right.$, and $\left.\mathrm{H}_{2} \mathrm{~S}\right)$, by infiltrating water through the waste pile and aerobic decomposition of waste matter. This is accompanied with elevated temperatures in the dump, which enhances ionic mobility and reduces electrical resistivity of the conductive leachate and relatively conductive waste gases in subsurface layers.

The endothermic phase is accompanied by the production of more waste gases than leachate, especially the nonconductive methane $\left(\mathrm{NH}_{4}\right)$ and non-methane volatile organic compounds (VOCs) by anaerobic decomposition of waste matter due to compaction effects and inhibition of the circulation of oxygen-rich air within the waste pile. This phase is characterized by reduced temperatures and increased concentration of non- conductive waste gases, which reduces ionic mobility and increases electrical resistivity of the subsurface.

This explains why the resistivities of leachate and waste gases are lower in the baseline than the monitor data, both spatially and temporally. This is especially pronounced along traverse B situated at the edge of the dumpsite for both surveys. This change in resistivity increases with offset from the dumpsite. These decrease with offset is attributed to natural attenuation processes of dilution and dispersion, variations in temperature with offset and soil physical properties which concentrate some solutes in preference to others.

Control survey exhibit intermediate resistivities relative to the traverses closer to the dumpsite. The waste gases dominate at this offset, while the impact of leachate has reduced.

\section{References}

[1] C.N. Ehirim and W. Ofor, Assessing Aquifer Vulnerability to Contaminants near Solid Waste Landfill Sites in a Coastal Environment, Port Harcourt, Nigeria. Trends in Applied Sciences Research: 6(2), 2011, 165-173.

[2] J.E. Chambers, O. Kuras, P.I. Meldrum, R.D. Ogilvy, and J. Hollands, Electrical Resistivity Tomography Applied to Hydrogeological and Engineering Investigations at a former Waste Disposal Site. Geophysics, 71, 2006, 231-239.

[3] A.R. Samsudeen, B.E.A. Rahim, and W.Z.W. Yaacob,: Mapping of Contamination Plumes at Municipal Solid Waste Disposal Sites Using Geoelectrical Imaging Technique: A Case Study in Malaysia. Journal of Spatial Hydrology. 6(2), 2006, 13-22.

[4] H. Rosqvist, T. Dahlin, A. Fourie, L. Rohrs, A. Bengtsson, and M. Larson, Mapping of Leachate Plumes at Two Landfills Sites in South Africa Using Geoelectrical Imaging Techniques. Proceedings of $9^{\text {th }}$ International Waste Management and Landfill Symposium, Caglian, Italy, On October $6^{\text {th }}-10^{\text {th }} 2003,2003,1-10$.

[5] C. Bernstone and T. Dahlin, Assessment of Two Automated DC Resistivity Acquisition Systems for Landfill Location Surveys: two case studies. Journal of Environmental and Engineering Geophysics. 4(2), 1999, 113-121.

[6] A.O. Greg, D.K. Michael, S.R. Partha, and J.L. Douglas, Time Lapse ERT Monitoring of an Injection/Withdrawal Experiment in a Shallow Unconfined Aquifer. Geophysics, 72(4), 2007, F117-F187.

[7] O. Bo, and L. Annika, Monitoring the Impact of De-Icing Salt on Road Sides Soils with Time Lapse Resistivity Measurements. Environmental Geophysics: 57, 2009, 217-229.

[8] C.N. Ehirim, J.O. Ebeniro, and O.P. Olanigan, A Geophysical Investigation of Solid Waste Landfill Using 2-D Resistivity Imaging and Vertical Electrical Sounding Methods in Port Harcourt Municipality, Rivers State, Nigeria. Pacific Journal of Science and Technology. 10(2), 2009b, 604-613.

[9] N.P. Iloeje, A New Geography of West Africa (Longman Group Ltd, Nigeria, 1972).

[10] K.C. Short and A.J. Stauble, Outline Geology of Nigeria (Ibadan University Press, Ibadan, Nigeria, 1967)

[11] M.H. Loke, Electrical Imaging Surveys for Environmental and Engineering Studies. A Practical Guide to 2- and 3-D Surveys. Advanced Geosciences, Inc.: Austin Tx. 1999, 57. 